\title{
Are giant clams (Tridacna maxima) distractible? A multi-modal study
}

\author{
Ryan Doyle $^{1}$, Jonnathan Kim ${ }^{1}$, Angelika Pe ${ }^{1}$, Daniel T Blumstein ${ }^{\text {Corresp. } 1}$ \\ ${ }^{1}$ Department of Ecology and Evolutionary Biology, University of California, Los Angeles, Los Angeles, CA, United States \\ Corresponding Author: Daniel T Blumstein \\ Email address: marmots@ucla.edu
}

To properly assess risk, an animal must focus its attention on relevant external stimuli; however, attention can be reallocated when distracting stimuli are present. This reallocation of attention may interfere with an individual's ability to effectively assess risk and may impede its response. Multiple stimuli presented together can have additive effects as distractors, and these include stimuli in different modalities. Although changes in noise and water flow are detectable by some bivalves, this has not been studied in the context of risk assessment or distraction. We experimentally exposed giant clams (Tridacna maxima) to changes in water particle movement through underwater sound (motorboat noise) and increased water flow to determine whether these stimuli, individually or together, modified risk assessment or caused distraction. We found that clams responded to sound, flow, and their combination by increasing frequency of mantle retractions (a potential anti-predator response) when exposed to a stimulus. Sound alone did not change risk assessment in either the latency to close or to reemerge following closure. However, when exposed to both stimuli simultaneously, clams increased their latency to close. We suggest that clams perceive sound and flow in an additive way, and are thus distracted. Interestingly, and uniquely, clams discriminate these multimodal stimuli through a single sensory modality. For sessile clams, anthropogenic noise is detectable, yet unavoidable, suggesting that they be especially vulnerable to marine noise pollution. 


\section{Are giant clams (Tridacna maxima) distractible? A} 2 multi-modal study.

3

4

5 Ryan Doyle ${ }^{1, *} \cdot$ Jonathan $\mathrm{Kim}^{1,{ }^{*}} \cdot$ Angelika $\mathrm{Pe}^{1,{ }^{*}} \cdot$ Daniel T. Blumstein ${ }^{1}$

6

$7{ }^{1}$ Department of Ecology and Evolutionary Biology, University of California, Los Angeles, 8 California USA

9

10

11 Corresponding Author:

12 Daniel T. Blumstein ${ }^{1}$

13 Department of Ecology and Evolutionary Biology, University of California, 621 Young Drive 14 South, Los Angeles, CA 90095-1606, USA

15 Email address: marmots@ucla.edu

16

17 *equal authorship contribution 


\section{Abstract}

20 To properly assess risk, an animal must focus its attention on relevant external stimuli; however,

21 attention can be reallocated when distracting stimuli are present. This reallocation of attention

22 may interfere with an individual's ability to effectively assess risk and may impede its response.

23 Multiple stimuli presented together can have additive effects as distractors, and these include

24 stimuli in different modalities. Although changes in noise and water flow are detectable by some

25 bivalves, this has not been studied in the context of risk assessment or distraction. We

26 experimentally exposed giant clams (Tridacna maxima) to changes in water particle movement

27 through underwater sound (motorboat noise) and increased water flow to determine whether

28 these stimuli, individually or together, modified risk assessment or caused distraction. We found

29 that clams responded to sound, flow, and their combination by increasing frequency of mantle

30 retractions (a potential anti-predator response) when exposed to a stimulus. Sound alone did not

31 change risk assessment in either the latency to close or to reemerge following closure. However,

32 when exposed to both stimuli simultaneously, clams increased their latency to close. We suggest

33 that clams perceive sound and flow in an additive way, and are thus distracted. Interestingly, and

34 uniquely, clams discriminate these multimodal stimuli through a single sensory modality. For

35 sessile clams, anthropogenic noise is detectable, yet unavoidable, suggesting that they be

36 especially vulnerable to marine noise pollution.

37

38 Keywords Multimodal • Giant Clam • Multisensory • Anthropogenic noise 39

40 Introduction 
41 Most animals experience some form of predation risk in their lifetimes (Lima \& Dill 1990).

42 Individuals must be able to properly assess risk of predation, weighing the costs and benefits of 43 either remaining or fleeing (Caro 2005). Flight or other forms of protection are often associated 44 with large energetic costs; individuals must expend energy to flee and lose out on potential 45 energy that could have been obtained through feeding (Ydenberg \& Dill 1986; Caro 2005). Attention is the process of filtering out irrelevant stimuli from the environment in order 47 for the individual to focus on biologically relevant stimuli (Dukas 2004). Attention to tasks and 48 external stimuli is limited, divisible and is sensitive to different modalities (Dukas 2004; Chan et 49 al. 2010; Blumstein 2013). External stimuli can interfere with risk assessment by both masking 50 biologically important signals (Zhou, Radford, \& Magrath 2019) and distracting individuals, thus 51 preventing them from focusing on avoiding predation (Rabin, Coss \& Owings 2006; Karp \& 52 Root 2009; Chan et al. 2010). Distraction can also impair performance on other relevant tasks 53 (Maes \& de Groot 2003); potentially reducing feeding and reproductive opportunities. External 54 acoustic and visual stimuli are commonly studied as distractions that impede anti-predatory 55 responses in vertebrates (Grueninger \& Pribram 1969; Dukas 2004; Wale, Simpson, \& Radford 56 2013). However, there is less literature on distraction in invertebrates. A growing literature on 57 giant clams' (Tridacna maxima) risk assessment shows that they respond to both visual and 58 tactile threats (Stasek 1965; Wilkens 1986; Land 2002; Soo \& Todd 2014; Johnson et al. 2016; 59 Dehaudt et al. 2019). However, bivalves assess risk in other modalities as well. They alter their anti-predator behaviors based on different chemical and auditory stimuli (Neo \& Todd 2011; Castorani \&

62 Hovel 2015; Peng et al. 2016). They possess labial palps on their mantle, gills and siphon that 63 can detect and respond to local water particle accelerations (Peng et al. 2016; Nedelec et al. 
64 2016). Their palps also allow them to sense pressure changes from underwater sound waves and

65 bivalves have been documented to significantly react to changes in underwater acoustic stimuli

66 (e.g., Mosher 1972; Peng et al. 2016; Shi et al. 2019; Charifi et al. 2018; Roberts et al. 2015).

67 Anthropogenic noise is one such external stimulus that could distract bivalves. Marine

68 anthropogenic noise has been steadily rising over recent years due to shipping, motorboat

69 activity, and pile-driving (Hildebrand 2009). There remains an overall lack of study regarding

70 the detrimental effects of noise with respect to invertebrates (Morley, Jones, \& Radford 2014)

71 and bivalves especially (Peng et al. 2016; Shei et al. 2019; Charifi et al. 2018; Roberts et al.

72 2015, Solan et al. 2016). Bivalves exposed to anthropogenic noise increase bioaccumulation of

73 toxic metals (Peng et al. 2016), alter their digging, sediment uptake and valve closure patterns

74 (Shei et al. 2019; Solan et al. 2016; Roberts et al. 2015) and experience reduced growth (Charifi

75 et al. 2018). However, these studies did not look specifically at how noise potentially distracts

76 bivalves from performing biologically important tasks. This research is critical because while

77 mobile animals can respond to noise pollution through movement and migration away from areas

78 of high intensity (Hirst \& Rodhouse 2000; Slabbekoorn et al. 2010), sessile marine invertebrates

79 lack escape as an option. Since these species may have important roles in their community (e.g.,

80 Jordan \& Valiela 1982; Carballo \& Naranjo 2002; Neo et al. 2015; Solan et al 2016), we need to

81 know more about how they may be negatively impacted by anthropogenic stimuli. The little

82 research that has been done calls for in situ testing and further understanding of the distracting

83 effects of anthropogenic noise (Aguilar de Soto et al. 2013; Buscaino et al. 2016).

84 Acoustic stimuli propagate waves that oscillate water particles without creating a clear

85 directional flow (Nedelec, Campbell \& Radford 2016); however these directional changes in

86 underwater flow could also distract bivalves. The effect of changes in water flow has been 
87 investigated in bivalves in terms of how it influences their feeding (Levinton 1991; Pilditch \&

88 Grant 1999). However, we are aware of no studies on changes in flow as a potential bivalve

89 distractor. Changes in water flow could indicate an increased potential for feeding; any increase

90 in underwater velocity could bring more edible plankton in the way of filter-feeding bivalves

91 (Levington 1991) thereby altering bivalves' risk versus reward perception. Flow changes could

92 also indicate changes in threat level because it is one of many factors naturally associated with

93 the presence of a moving predator (McHenry et al. 2009).

94 Giant clams may commonly experience both stimuli in a multimodal way. Multimodal

95 assessment may provide more information about threats and hence reduce uncertainty about risk

96 leading to an increase or decrease in anti-predator responses (Munoz \& Blumstein 2012). Most

97 multimodal research has explored the additive effect of multiple stimuli as a multisensory

98 experience (Munoz \& Blumstein 2012, 2019). Whereas a combination of sound and flow will

99 indeed be considered multimodal, giant clams experience changes in water particle motion

100 through a single sensory channel: their palps. If clams respond differently to multimodal

101 stimulation compared to unimodal stimulation, then this will indicate that giant clams could

102 modify their anti-predator behavior in a multimodal way and that this was achieved by a single

103 sensory pathway binding multimodal stimuli. Specifically, the presence of additional stimuli in

104 the form of sound or flow could potentially distract giant clams from the presence of a predator, 105 causing a delay in how fast they retract their mantle.

106 We asked whether changes in water particle motion due to unimodal sound, unimodal 107 water flow, or a multimodal combination of the two would distract giant clams or modify their

108 risk assessment. When perturbed, giant clams will partially or fully retract their mantle as a

109 potential anti-predatory response (Johnson et al. 2016; Dehaudt et al. 2019; Land 2002; Wilkens 
110 1986). Thus, we used the latency to fully retract their mantle as an indicator of distraction levels

111 and the latency for the mantle to fully re-emerge from its shell as a measure of perceived risk.

112

\section{Materials \& Methods}

114

115 Study subjects.

116 We marked giant clams $(n=32)$ for subsequent study within Gump Reef in Cook’s Bay,

117 Mo'orea, French Polynesia (-17.482215, -149.827079), a marine protected area that has been the

118 site of previous studies of clam anti-predator behavior (Johnson et al. 2016; Dehaudt et al. 2019).

119 Each clam was $>5 \mathrm{~m}$ apart from each other. We measured each clam's depth and the length of the 120 each clam's shell. Clams received four total treatments over four separate days (with a planned 121 day off between subsequent treatments) in a Latin square design: control, flow only, sound only, 122 and flow and sound together. We initially planned to conduct all experiments over 8 days, but a 123 large storm generated considerable runoff which filled the bay with sediment and created poor 124 visibility making it impossible to study the clams. Thus, we waited until the water cleared and 125 thus conducted two treatments 3 days later than planned. We refer to the first two treatments as 126 pre-plume and the second two treatments as post-plume. Data were collected in the mornings, 127 except for one day in which data had to collected in the afternoon due to water clarity issues 128 from storm water runoff. Clams were studied under permits issued by the Government of French 129 Polynesia (permit approved on 21 November 2019).

131 Flow Calibration. 
132 We used an underwater aquarium pump (1/55 HP, ECO-FLO, Ashland OH) to manipulate water

133 velocity over the clam. Before experimentation, we calibrated flow by video recording

134 (Crosstour CT7000 underwater video camera, Shenzhen, China) the time it took red dye to travel

$13510 \mathrm{~cm}$ through a clear, plastic tube. We measured the velocity to be $0.43( \pm 0.06 \mathrm{SD}) \mathrm{m} / \mathrm{s}(\mathrm{N}=10$

136 measurements) where the jet exiting the nozzle of the pump was $15 \mathrm{~cm}$ away from the opening

137 of the tube.

138

139 Sound Calibration.

140 We used an Oceanears DRS-8 MOD 2 underwater speaker (North Canton, OH) to broadcast

141 recordings of outboard motorboats collected underwater. Five recordings of motorboat sounds of

142 similar amplitude were obtained from a previous study (Simpson et al. 2016). The five motorboat

143 recordings consist of a research vessel (5-m-long aluminum hull boat with 30 hp Suzuki

144 outboard motors) motoring 10-200 m away from the hydrophone at various speeds, mimicking

145 boat operations that are common in coral reef environments (Simpson et al. 2016).

146 To determine how the broadcast sounds compared to that of the reef environment, we

147 broadcast and re-recorded our exemplars underwater using a Wildlife Acoustics Song Meter

148 SM2+ (Concord, MA) with a Wildlife Acoustics hydrophone. We first calibrated the hydrophone

149 by playing $45 \mathrm{~s}$ of white noise of a known amplitude ( $90 \mathrm{~dB}$ re $20 \mu \mathrm{Pa}$ measured at $1 \mathrm{~m})$ through

150 an Oceanears DRS-8 MOD 2 underwater speaker (North Canton, OH) above water. The white

151 noise was generated in Audacity (version 2.3.3, 2019) and was measured with a Radioshack (33-

152 2055) Digital Sound Level Meter set to weighting A (Radioshack, Fort Worth, Texas) placed 1

153 m away from the speaker. The white noise was then broadcast underwater $1 \mathrm{~m}$ from the

154 hydrophone at $0.5 \mathrm{~m}$ depth. We also similarly broadcasted the five motorboat exemplars (89-91 
$155 \mathrm{~dB}$ re $20 \mu \mathrm{Pa}$ measured at $1 \mathrm{~m}$ ) against the calibrated hydrophone. In Praat (version 6.1.109,

156 2020), we calculated the average intensity (minimum pitch $=100 \mathrm{~Hz}$ ) of the white noise and then

157 adjusted the scale to reflect the intensity measured above water to which we added $61.5 \mathrm{~dB}$ to

158 roughly estimate intensity re $1 \mu \mathrm{Pa}$ underwater (National Research Council 1994, Gausland

159 2000). This created a scaling factor that we used to adjust the amplitude of each motorboat

160 exemplar. Using Praat, we calculated the average intensity of our stimuli across exemplars, 161 which was $150.6 \mathrm{~dB}( \pm 1.03 \mathrm{SD})$ re $1 \mu \mathrm{Pa}$.

162

163 Stimulus presentation.

164 Clams received four different treatments over four days: control (pump and speaker off), flow

165 only (pump on, speaker off), sound only (pump off, speaker on) and flow and sound (pump and 166 speaker on) in a Latin Square design. For all four treatments, the clam was subjected to the

167 presence of both the pump and speaker, whether on or off, for $60 \mathrm{~s}$ before it was perturbed. The 168 pump and speaker were attached to a $1.5 \mathrm{~m}$ PVC pipe. The hose from the pump was positioned

$16915 \mathrm{~cm}$ away from the clam while the speaker was $1 \mathrm{~m}$ away pointed at the center of the clam's

170 mantle. This ensured that the clam was subjected to $0.4( \pm 0.07 \mathrm{SD}) \mathrm{m} / \mathrm{s}$ of flow and $149.13 \mathrm{~dB}$

$171( \pm 1.03 \mathrm{SD})$ re $1 \mu \mathrm{Pa}$. Clams receiving sound or flow and sound treatment were randomly

172 exposed to one of five motor boat noises.

173 During this $60 \mathrm{~s}$ period before perturbation, we counted the number of mantle twitches

174 (partial retractions) as an indicator of perceived threat. The entire length of the clam's mantle

175 was then rubbed back and forth twice using a pencil's eraser attached to a different $2 \mathrm{~m}$ long

176 PVC pipe that permitted the person to be $\geq 1 \mathrm{~m}$ away. The latency to close was recorded using

177 either Crosstour CT7000 or a GoPro Hero 4 camera. The latency to re-open was measured both 
178 in the field using a digital stopwatch, and using the camera. We defined latency to close as the

179 first sign of retraction of the mantle to the point where the clam is fully or almost closed. We

180 defined latency to reemerge as the time from the first contact of the pencil to the clam returning

181 to its previous undisturbed state that the observer has determined prior to the clam being rubbed.

182 If the clam did not fully reemerge within $3 \mathrm{~min}$, we determined reemergence as the point where

183 its mantle was most fully extended. The camera recorded the entire process from the $60 \mathrm{~s}$ before

184 perturbation until the observer was confident the clam had fully reemerged. In 16 cases we were

185 unable to confidently measure the latency to re-open in the field. Due to the extremely high

186 correlation between field and camera playback latency times, we estimated these recorded times

187 from field observations using a prediction equation based on the correlation between

188 measurements (estimated time recorded from video $=1.0263 *$ stopwatch time $+1.9489 ; R^{2}=$

$1890.98 ; p<0.001, N=103$ measurements to estimate latency to re-emerge).

190 To reduce experimental interference, we did not record the precise velocity of ambient

191 water flow during the experiments. However, we noted flow as either negligible or noticeable by

192 observing pieces of macroalgae moving underwater after conducting each experimental

193 treatment. If pieces of macroalgae in the water column at the same depth of the clam moved in a

194 single direction, flow was marked as noticeable. We estimated an upper limit range of ambient

195 velocity during testing by recording the velocity at which a piece of macroalgae moved $10 \mathrm{~cm}$

196 through a clear, plastic tube with a GoPro nine separate times during a day with particularly high

197 underwater flow. We estimated this velocity as $0.09( \pm 0.064 \mathrm{SD}) \mathrm{m} / \mathrm{s}$, which was substantially

198 lower than our experimental velocity. Thus, we infer that our experimental velocity was

199 substantially greater than background changes in flow. 


\section{Statistical analysis.}

202 Prior to analysis, we plotted histograms of variables to check for normality and $\log _{10}$ transformed

203 retractions and latency to re-emerge.

204 To determine if stimuli were detected by giant clams, we fitted a linear mixed model with

205 the number of retractions as the dependent variable using the lme4 version 1.1-21, (Bates et al.

206 2019) and lmerTest version 3.1-1 (Kuznetsova, Brokhoff, \& Christensen 2017) packages in R

207 version 3.6.2 (R Core Team 2019). Treatment, trial number, clam size, and plume presence

208 (defined as before or after the disruptive plume) were added as fixed effects. To account for 209 repeated measures, subject ID was added as a random effect. We tested the assumptions of our

210 mixed model by plotting a histogram of residuals (they were approximately normal), plotting a

211 q-q plot (they were approximately linear), and plotting fitted versus predicted values (there was

212 no obvious pattern). We also compared our model to a linear model without subject ID as a

213 random effect to determine if there was a significant difference in individuals' number of

214 retractions. We estimated marginal means using the MuMIn version 1.43.15 (Barton 2019) and

215 emmeans version 1.4.4 (Lenth et al. 2020) packages in $\mathrm{R}$ and estimated the $\mathrm{d}$-score as a measure

216 of treatment effect size. We plotted estimated marginal means using plotly version 4.9.2 (Sievert

217 et al. 2020).

218 To determine if multimodal stimuli distracted giant clams, we fitted a linear mixed model

219 as above with the latency to close, and another model with the latency to re-emerge as dependent

220 variables. Again, we added treatment, trial number, clam size, and plume presence as fixed

221 effects and added subject ID as a random effect. Model fit was determined by examining the

222 normality of residuals in a histogram and quantile plot. Again, both models were compared to a 
223 linear model without the random effect of subject ID. Estimated marginal means were plotted 224 with standard errors.

225 We tested for exemplar effects by creating a dataset containing only those where

226 motorboat noise was used and then fitting each of our models with sound exemplar as a fixed

227 factor to determine if any variation in response was explained by the specific exemplar used.

228 All data and code are contained in Supplementary Tables 1 and 2. Throughout, we set our 229 alpha to 0.05 , and thus interpret $\mathrm{p}<0.05$ as significant.

230

231 Results

232 After controlling for significant random effects explained by individual (Chi-square $=2.83,1 \mathrm{df}$, $233 p=0.007)$, and non-significant fixed effects of trial number, plume presence and clam size, there 234 were more twitches recorded during a $60 \mathrm{~s}$ period when clams were exposed to sound, flow and 235 the combination of the two stimuli compared to the no stimuli treatment (Table 1a, Linear mixed 236 effects model, $p<0.05$ for all). There were large effect sizes between the control and each 237 treatment (Fig. 1a, Supplementary Table 3; $d>0.75$ ). Additionally, there were moderate effect 238 sizes $(0.75>d>0.4)$ between unimodal sound and unimodal flow as well as between unimodal 239 sound and multimodal flow and sound (Fig. 1a, Supplementary Table 3). After controlling for significant random effects explained by individual (Chi-square $=$

$24110.848,1 \mathrm{df}, p<0.001$ ), significant fixed effects of clam size, and non-significant fixed effects

242 of trial number and plume presence, we found that the multimodal treatment (combination of 243 sound and flow) significantly increased clams' latency to close (Table 1b, Linear mixed effects 244 model, $p<0.05$ ) while the other two unimodal treatments (flow only and sound only) had no 245 effect on latency to close when compared to the control (Table 1b, Linear mixed effects model, $p$ 
$246>0.05)$. There was a small to moderate effect size between multimodal flow and sound and the

247 control; all other comparisons had small effect sizes (Fig. 1b, Table $1 \mathrm{~b} ; d=0.35$ and $d<0.3$,

248 respectively).

249 After controlling for significant random effects explained by individual (Chi-square $=$

$25022.442,1 \mathrm{df}, p<0.001)$, significant fixed effects of plume presence and non-significant fixed

251 effects of trial number and clam size, we found that clams did not significantly change their

252 latency to reemerge after treatments when compared to the control (Table 1c, Linear mixed

253 effects model, $\mathrm{p}>0.05$ for all). We found moderate effect sizes $(0.75>d>0.4)$ between

254 unimodal flow treatment compared to all other treatments as well as the control.

255 When we tested for exemplar effects, variation in sound exemplars did not explain any

256 variation in clam response.

257

\section{Discussion}

259 Animals often use cues from a variety of modalities to reduce uncertainty about their

260

environment (Dall \& Johnstone 2002), which potentially permits more precise assessments of

261 risk. Here we used two stimuli, from different modalities, either alone or together, to study anti-

262 predator responses in clams. We found that clams increased their frequency of partial retractions

263 during the $60 \mathrm{~s}$ acclimation period after exposure to any treatment. Clam mantle retraction is

264 presumably a discrete anti-predator response used for protection and to scare potential predators

265 with the water expelled from its siphon during retraction (Wilkens 1986; Land 2002).

266 While twitches were not complete valve closures, the twitches were still a physical response that

267 is closely linked to the species' highest level antipredator response - full mantel closure.

268 Increased anti-predator behavior indicates that motorboat noise may act as a giant clam stressor 
269 (Wright et al. 2007). Previous studies have shown the adverse effects of anthropogenic noise on

270 bivalves' physiological processes such as metabolism and growth rate (Roberts et al. 2015; Peng

271 et al. 2016; Charifi et al. 2018; Shi et al. 2019). Thus, our results add to previous studies in

272 assessing whether the affected physiological processes in bivalves are the result of anthropogenic

273 noise-based distraction.

274 Sound and flow did not significantly alter clams' latency to close when tested as separate

275 unimodal treatments. However, when sound and flow were presented together as a multimodal

276 stimulus, clams closed more slowly, indicating that the presentation of multiple stimuli can be

277 distracting. Given that there was no significant effect of each stimulus when presented on its own

278 and that giant clams perceive both stimuli through their palps, a unisensory receptor, we

279 conclude that these stimuli have an additive effect on compromising clams' attention. These

280 results are consistent with the distracted prey hypothesis in which peripheral stimuli may

281 compromise an individual's attention from biologically necessary tasks (Chan et al. 2010). Less

282 vigilant prey become more likely targets for predators (Krause \& Godin 1996), and a slower

283 closing time in clams encountering a multimodal stimulus indicates that distracted clams may be

284 more vulnerable to predatory damage.

285 Clams did not differ in their reemergence time between exposure to treatment and

286 control. However, the flow as a unimodal treatment had a modest, but not significant, decrease in

287 reemergence time from the control (Table 1c) and had a moderate to large effect size when

288 compared to unimodal sound and multimodal sound and flow. This modest decrease in

289 reemergence time in response to increased flow around the clam may indicate an increased

290 opportunity to filter feed because there are more sediments and nutrients moving through its

291 environment (Taghon, Nowell, \& Jumars 1980; Trager, Hwang, \& Strickler 1990; Skilleter \& 
292 Peterson 1994, Hardy \& Hardy 1969, Hawkins \& Klumpp 1995). Thus, clams may reemerge 293 faster to take advantage of increased nutrient availability. As a result, increased water flow 294 cannot be considered a neutral distractor. It is rather unique in that it is a biologically significant 295 stimulus, forcing clams to factor foraging opportunity into their decision-making process. Clams 296 must simultaneously manage predation risk and obtain energy through feeding behavior: two 297 potentially exclusive behaviors with their own set of benefits and consequences. If clams 298 reemerge sooner, they could potentially make the mistake of exposing themselves to predators; 299 however, if they stay closed for too long, they are missing out on feeding opportunities. Further 300 studies are needed that explore reemergence time of clams in areas with naturally high levels of 301 flow to determine if they behave differently from clams in areas, like our study site on Gump 302 Reef, with relatively low flow. These findings further illustrate the negative effects that anthropogenic noise can have on 304 bivalves (Peng et al. 2016; Shi et al. 2019; Charifi et al. 2018; Roberts et al. 2015). These prior 305 studies identified alterations in essential processes such as digging behavior, metabolism, and 306 growth in bivalves (Peng et al. 2016; Shi et al. 2019; Charifi et al. 2018). Of the prior studies that 307 identified negative effects, none, until this one, specifically focused on anthropogenic noise as a 308 distraction. A recent meta-analysis reported anthropogenic noise negatively affects families 309 across the animal kingdom, potentially altering distribution, communication, foraging, and 310 homeostasis in these families (Kunc \& Schmidt 2020). However, species' responses differ 311 widely based on ecological context and physical constraints (Wright et al. 2007). While mobile 312 species can avoid anthropogenic noise stressors (e.g., Francis, Ortega, \& Cruz 2009; Francis et 313 al. 2011; Goodwin \& Schriver 2011; Nowacek et al. 2007; Weilgart 2007, 2018), giant clams 314 are, for the most part, sessile and must endure any anthropogenic disturbance. Giant clams play 
315 important ecological roles on coral reefs, including water filtration and nutrient sequestration

316 (Neo et al. 2015). Thus, anything that makes more clams more vulnerable to predators may

317 contribute to the loss of these important services that giant clams provide.

318 Multimodal stimuli are traditionally defined as separate stimuli that are perceived through

319 different sensory channels (Partan \& Marler 2005). Many animals are able to detect multiple

320 stimuli across different modalities and create a unified percept by integrating them (Brown \&

321 Magnavacca 2003; Partan et al. 2010). In contrast to all other studies we are aware of, giant

322 clams perceive multimodal stimuli through a single sensory modality, their palps, but

323 nevertheless integrated these stimuli. It is important to note that giant clams depend heavily on

324 visual cues for risk assessment (Wilkens 1986, Stasek 1965). Our manipulations did not create

325 any shading events or cause any visible turbulence, thus we infer that clams were not relying on

326 visual cues to sense the particle motion caused by noise or flow. We therefore suggest that local

327 changes in water flow and changes in underwater noise are indeed multimodal although

328 perceived through a single sensory channel by clams. The clams' ability to react differently to

329 either unimodal or multimodal treatments of sound and flow is a novel example of how animals

330 can bind multimodal stimulus together through a single sensory pathway to modify their risk

331 assessment.

332 Sound and flow changes sensed by clams could also be viewed as multi-attribute stimuli.

333 Unlike multimodal stimuli, which are typically perceived through different sensory channels,

334 multi-attribute stimuli are perceived through a single sensory channel. Multi-attribute stimuli are

335 often studied in bioacoustics (e.g., Gerhardt 1992; Castellano \& Rosso 2007; Naguib \& Wiley

336 2001; Gerhardt \& Schul 1999; Kershenbaum et al. 2016). In these cases, different components of

337 an acoustic signal, including rate and frequency rises, can send multiple messages or further 
338 inform an individual. Previous studies on crayfish (Orconectes virilis) demonstrated that animals

339 can use multiple separate chemical cues perceived through a single olfactory channel (Hazlett

340 1999; Bouwma \& Hazlett 2001). Female Italian treefrogs (Hyla intermedia) weight separate

341 components of male mating calls differently when selecting a mate (Castellano \& Rosso 2007).

342 Similarly, great tits (Parus major) assess multiple acoustic attributes of song (Weary 1990).

343 Female bluehead wrasse (Thalassoma bifasciatum) use multiple visual cues, such as coloration

344 and courtship display, to assess risk (Warner \& Dill 2000). In honeybees, different olfactory

345 stimuli are processed through different clusters of glomeruli, enabling them to process different

346 components of odor through different pathways (Abel, Rybak, \& Menzel 2001; Kirschner et al.

347 2006). The majority of these previous studies have focused on multi-attribute signaling and not

348 strictly multi-attribute risk assessment (Munoz \& Blumstein 2012, 2019). In addition, these

349 previous studies focused mainly on terrestrial organisms; more studies are needed on multi-

350 attribute stimulus assessment in marine organisms. We have shown that giant clams can bind

351 together multiple stimuli into one sensory channel, an ability that we suspect is shared with other 352 species.

353

354 Conclusions

355 Giant clams increased their frequency of mantle retractions, a potential anti-predator behavior, in 356 response to motorboat playback, increased flow and the combination of the two. Clams also

357 slowed their closing times when exposed to a combination of sound and flow, indicating

358 distraction through multimodal means. These findings add evidence to the deleterious nature of 359 anthropogenic noise on sessile marine invertebrates and present a novel case of multimodal 
360 stimuli processed together through a single sensory channel. We recommend further study of

361 unisensory systems and their relationships to traditionally multimodal stimuli.

362

\section{Acknowledgements}

364

365

366

367

368

369

370

371

372

373

374

375

376

377

378

379

380

381

382

383

384

385

386

387

388

389

390

391

392

393

We thank the UCLA Department of Ecology and Evolutionary Biology for partial support, the

Richard Gump South Pacific Research Station for logistical support, Zachary Schakner for the playback equipment, Maud Ferrari for motorboat recordings, John Milligan and Vivian Kim for

help with our equipment, and Dana Williams for logistical and statistical help as well as

comments on a previous version of this MS. The manuscript was improved by addressing the

comments of three astute reviewers.

\section{References}

Abel R, Rybak J, Menzel R. 2001. Structure and response patterns of olfactory interneurons in the honeybee, Apis mellifera. Journal of Comparativve Neurology 437: 363-383.

Aguilar de Soto NA, Delorme N, Atkins J, Howard S, Williams J, Johnson M. 2013. Anthropogenic noise causes body malformations and delays development in marine larvae. Science Reports 3:2831.

Barton, Kamil. 2019. MuMIn: multi-model inference. R package version, 1.43.6

Bates D, Maechler M, Bolker B, Walker S. 2014. Linear mixed-effects models using 'eigen' and S4. Journal of Statistical Software 67:1-48.

Blumstein DT. 2013. Attention, habituation, and antipredator behaviour: implications for urban birds. In: Gil D, Brumm H (ed) Avian urban ecology: behavioural and physiological adaptations. Oxford. 41-53

Bouwma P, Hazlett BA. 2001. Integration of multiple predator cues by the crayfish Orconectes propinquus. Animal Behaviour 61:771-776

Brown GE, Magnavacca G. 2003. Predator inspection behaviour in a characin fish: an interaction between chemical and visual information? Ethology 109:739-750

Buscaino G, Ceraulo M, Pieretti N, Corrias V, Farina A, Filiciotto F, Maccarrone V, Grammauta R, Caruso F, Giuseppe A, Mazzola S. 2016. Temporal patterns in the soundscape of the shallow waters of a Mediterranean marine protected area. Science Report 6:34230.

Carballo JL, Naranjo S. 2002. Environmental assessment of a large industrial marine complex based on a community of benthic filter-feeders. Marine Pollution Bulletin 44:605-610

Caro T. 2005. Antipredator defenses in birds and mammals. University of Chicago Press; Chicago, IL.

Peer] reviewing PDF | (2020:05:48935:2:0:NEW 2 Sep 2020) 
394

395

396

397

398

399

400

401

402

403

404

405

406

407

408

409

410

411

412

413

414

415

416

417

418

419

420

421

422

423

424

425

426

427

428

429

430

431

432

433

434

435

436

437

438
Castellano S, Rosso A. 2007. Female preferences for multiple attributes in the acoustic signals of the Italian treefrog, Hyla intermedia. Behavioral Ecology and Sociobiology 61:1293-1302

Castorani MCN, Hovel KA. 2015. Native predator chemical cues induce anti-predation behaviors in an invasive marine bivalve. Biological Invasions 18:169-181.

Chan AAYH, Giraldo-Perez P, Smith S, Blumstein DT. 2010. Anthropogenic noise affects risk assessment and attention: the distracted prey hypothesis. Biology Letters 6:458-461

Charifi M, Miserazzi A, Sow M, Perrigault M, Gonzalez P, Ciret P, Benomar, S, Massabuau J. 2018. Noise pollution limits metal bioaccumulation and growth rate in a filter feeder, the Pacific oyster Magallana gigas. PLOS One 13:e0194174.

Dall SRX, Johnstone RA. 2002. Managing uncertainty: Information and insurance under the risk of starvation. Philosophical Transactions of the Royal Society B Biological Sciences 357:1519-1526.

Dehaudt B, Nguyen M, Vadlamudi A, Blumstein DT. 2019. Giant clams discriminate threats along a risk gradient and display varying habituation rates to different stimuli. Ethology 125:392-398.

Dukas R. 2004. Causes and consequences of limited attention. Brain, Behavior and Evolution 63:197-210.

Francis CD, Ortega CP, Cruz A. 2009. Noise pollution changes avian communities and species interactions. Current Biology 19:1415-1419.

Francis CD, Paritsis J, Ortega CP, Cruz A. 2011. Landscape patterns of avian habitat use and nest success are affected by chronic gas well compressor noise. Landscape Ecology 26:12691280.

Gausland, I. 2000. Impact of seismic surveys on marine life. The Leading Edge 19:903-905.

Gerhardt HC. 1992. Multiple messages in acoustic signals. Seminars in Neuroscience 4:391-400.

Gerhardt HC, Schul J. 1999. A quantitative analysis of behavioral selectivity for pulse rise-time in the gray treefrog, Hyla versicolor. Journal of Comparative Physiology A 185:33-40.

Goodwin SE, Shriver WG. 2011. Effects of traffic noise on occupancy patterns of forest birds. Conservervation Biology 25:406-411.

Grueninger WE, Pribram KH. 1969. Effects of spatial and nonspatial distractors on performance latency of monkeys with frontal lesions. Journal of Comparative and Physiological Psychology 68:203-209.

Hardy JT, Hardy SA. 1969. Ecology of Tridacna in Palau. Pacific Science. 23: 467-472.

Hawkins AJS, Klumpp DW. Nutrition of the giant glam Tridacna gigas (L.). II. Relative contributions of filter-feeding and the ammonium-nitrogen acquired and recycled by symbiotic alga towards total nitrogen requirements for tissue growth and metabolism. Journal of Experimental Marine Biology and Ecology. 190: 263-290.

Hazlett BA. 1999. Responses to multiple chemical cues by the crayfish Orconectes virilis. Behaviour 136:161-171.

Hildebrand JA. 2009. Anthropogenic and natural sources of ambient noise in the ocean. Marine Ecology Progress Series 395:5-20.

Hirst AG, Rodhouse PG. 2000. Impacts of geophysical seismic surveying on fishing success. Reviews in Fish Biology and Fisheries. 10:113-118.

Johnson GC, Karajah MT, Mayo K, Armenta TC, Blumstein DT. The bigger they are the better they taste: size predicts predation risk and anti-predator behavior in giant clams. Journal of Zoology 301:102-107.

Peer] reviewing PDF | (2020:05:48935:2:0:NEW 2 Sep 2020) 
439

440

441

442

443

444

445

446

447

448

449

450

451

452

453

454

455

456

457

458

459

460

461

462

463

464

465

466

467

468

469

470

471

472

473

474

475

476

477

478

479

480

481

482

483
Jordan TE, Valiela I. 1982. A nitrogen budget of the ribbed mussel, Geukensia demissa, and its significance in nitrogen flow in a New England salt marsh. Limnology and Oceanography 27:75-90.

Karp DS, Root TL. 2009. Sound the stressor: How hoatzins (Opisthocomus hoazin) react to ecotourist conversation. Biodiversity and Conservation 18:3733-3742.

Kershenbaum A, Blumstein DT, Roch MA, Acay C, Backus G, Bee MA, Bohn K, Cao Y, Carter C, Casar C, Coen M, DeRuiter SL, Doyle L, Edelman S, Ferrer-i-Cancho R, Freeberg TM, Garland EC, Gustison M, Harley HE, Huetz C, Hughes M, Bruno JH, Ilany A, Jin DZ, Johnson M, Ju C, Karnowski J, Lohr B, Manser MB, McCowan B, Mercado III, E, Narins PM, Piel A, Rice M, Salmi R, Sasahara K, Sayigh L, Shiu Y, Taylor C, Vallejo EE. Waller S, Zamora-Guiterrez V. 2016. Acoustic sequences in non-human animals: a tutorial review and prospectus. Biological Reviews 91:13-52.

Kirschner S, Kleineidam CJ, Zube C, Rybak J, Grunewald B, Rossler W. 2006. Dual olfactory pathway in the honeybee, Apis mellifera. Journal of Comparaative Neurology 499: 933-952.

Krause J, Godin JGJ. 1996. Influence of prey foraging posture on flight behavior and predation risk: Predators take advantage of unwary prey. Behavioural Ecology 7:264-271.

Kunc HP, Schmidt R. 2019. The effects of anthropogenic noise on animals: A meta-analysis. Biology Letters 15: 20190649.

Kuznetsova A, Brockhoff PB, Christensen RHB. 2017. Tests in linear mixed effects models. Journal of Statistical Software 82:1-26.

Land MF. 2002. The spatial resolution of the pinhole eyes of giant clams (Tridacna maxima). Proceedings of the Royal Society B: Biological Sciences 270:185-188.

Lenth R, Singmann H, Love J, Buerkner P, Herve M. 2020. Estimated marginal means, aka leastsquares means. URL https://CRAN.R-project.org/package=emmeans.

Levinton JS. 1991. Variable feeding behavior in three species of Macoma (Bivalvia: Tellinacea) as a response to water flow and sediment transport. Marine Biology 110:375-383.

Lima SL, Dill LM. 1990. Behavioral decisions made under the risk of predation: a review and prospectus. Canadian Journal of Zoology 68: 619-640.

Maes JHR, de Groot G. Effects of noise on the performance of rats in an operant discrimination task. Behavioural Processes. 61:57-68.

McHenry MJ, Feitl KE, Strother JA, Van Trump WJ. 2009. Larval zebrafish rapidly sense the water flow of a predator's strike. Biology letters. 5: 477-479.

Morley EL, Jones G, Radford AN. 2014. The importance of invertebrates when considering the impacts of anthropogenic noise. Proceedings of the Royal Society B: Biological Sciences 281:20132683.

Mosher JI. 1972. The responses of Macoma balthica (Bivalvia) to vibrations. Journal of Molluscan Studies 40: 125-131.

Munoz NE, Blumstein DT. 2012. Multisensory perception in uncertain environments. Behavioural Ecology 23:457-462.

Munoz NE, Blumstein DT. 2019. Optimal multisensory integration. Behavioural Ecology 23: 457-462.

Naguib M, Wiley RH. 2001. Review: Estimating the distance to a source of sound: mechanisms and adaptations for long-range communication. Animal Behavior 62:825-837.

National Research Council. 1994. Low-Frequency Sound and Marine Mammals: Current Knowledge and Research Needs. Washington DC: The National Academies Press.

Peer] reviewing PDF | (2020:05:48935:2:0:NEW 2 Sep 2020) 
484

485

486

487

488

489

490

491

492

493

494

495

496

497

498

499

500

501

502

503

504

505

506

507

508

509

510

511

512

513

514

515

516

517

518

519

520

521

522

523

524

525

526

527

528

529

Nedelec SL, Campbell J, Radford AN, Simpson SD, Merchant ND. 2016. Particle motion: the missing link in underwater acoustic ecology. Methods in Ecology and Evolution 7:836-842.

Neo ML, Eckman W, Vicentuan K, Teo SLM, Todd PA. 2015. The ecological significance of giant clams in coral reef ecosystems. Biological Conservation 181:111-123.

Neo ML, Todd PA. 2011. Predator-induced charges in fluted giant clam (Tridacna squamosa) shell morphology. Journal of Experimental Marine Biology and Ecology. 397: 21-26

Nowacek DP, Thorne LH, Johnston DW, Tyack PL. 2007. Responses of cetaceans to anthropogenic noise. Mammal Review 37:81-115.

Partan SR, Fulmer AG, Gounard MAM, Redmond JE. 2010. Multimodal alarm behavior in urban and rural gray squirrels studied by means of observation and a mechanical robot. Current Zoology 56:313-326.

Partan SR, Marler P. 2005. Issues in the classification of multimodal communication signals. The American Naturalist 166:231-245.

Peng C, Zhao X, Liu S, Shi W, Han Y, Guo C, Jiang J, Wan H, Shen T, Guangxu L. 2016. Effects of anthropogenic sound on digging behavior, metabolism, Ca 2+/Mg 2+ ATPase activity, and metabolism-related gene expression of the bivalve Sinonovacula constricta. Science Reports 6:24266.

Pilditch CA, Grant J. 1999. Effect of variations in flow velocity and phytoplankton concentration on sea scallop (Placopecten magellanicus) grazing rates. Journal of Experimental Marine Biology and Ecology 240:111-136.

Rabin LA, Coss RG, Owings DH. 2006. The effects of wind turbines on antipredator behavior in California ground squirrels (Spermophilus beecheyi). Biological Conservation 131:410-420.

R Core Team. 2019. R: A language and environment for statistical computing. R Foundation for Statistical Computing, Vienna, Austria. URL https:/www.R-project.org/.

Roberts L, Cheesman S, Breithaupt T, Elliott M. 2015. Sensitivity of the mussel Mytilus edulis to substrate-borne vibration in relation to anthropogenically generated noise. Marine Ecology Progress Series 538:185-195.

Shi W, Han Y, Guan X, Rong J, Du X, Zha S, Tang Y, Liu G. 2019. Anthropogenic noise aggravates the toxicity of cadmium on some physiological characteristics of the blood clam Tegillarca granosa. Frontiers in Physiology 10:3389.

Sievert C, Parmer C, Hocking T, Chamberlain S, Ram K, Corvellec M, Despouy P. 2020. Create Interactive WebGraphics via 'plotly.js'. URL https:/CRAN.R-project.org/package=plotly.

Simpson SD, Radford AN, Nedelec SL, Ferrari MCO, Chivers DP, McCormick MI, Meekan MG. 2016. Anthropogenic noise increases fish mortality by predation. Nature Communications 7:10544.

Skilleter GA, Peterson CH. 1994. Control of foraging behavior of individuals within an ecosystem context: the clam Macoma balthica and interactions between competition and siphon cropping. Oecologia 100:268-278.

Slabbekoorn H, Bouton N, van Opzeeland I, Coers A, ten Cate C, Popper AN. 2010. A noisy spring: the impact of globally rising underwater sound levels on fish. Trends in Ecology and Evolution 25:419-427.

Solan M, Hauton C, Godbold JA, Wood CL, Leighton TG, White P. 2016. Anthropogenic sources of underwater sound can modify how sediment-dwelling invertebrates mediate ecosystem properties. Scientific Reports 6: 20540

Soo P, Todd PA 2014. The behaviour of giant clams (Bivalvia: Cardiiadae: Triadcninae). Marine Biology 161: 2699-2717.

Peer] reviewing PDF | (2020:05:48935:2:0:NEW 2 Sep 2020) 
530 Stasek CR. 1965. Behavioural adaptation of the giant clam Tridacna maxima to the presence of

531

532

533

534

535

536

537

538

539

540

541

542

543

544

545

546

547

548

549

550

551

552

553

554

555

556

557 grazing fishes. Veilger 8:29-35.

Taghon GL, Nowell ARM, Jumars PA. 1980. Induction of suspension feeding in spionid polychaetes by high particulate fluxes. Science 210:562-564.

Trager GC, Hwang JS, Strickler JR. 1990. Barnacle suspension-feeding in variable flow. Marine Biology 105:117-127.

Wale MA, Simpson SD, Radford AN. 2013. Noise negatively affects foraging and antipredator behaviour in shore crabs. Animal Behavior 86:111-118.

Warner RR, Dill LM. 2000. Courtship displays and coloration as indicators of safety rather than of male quality: the safety assurance hypothesis. Behavioural Ecology 11:444-451.

Weary DM. 1990. Categorization of song notes in great tits: which acoustic features are used and why? Animal Behavior 39:450-457.

Weilgart LS. 2007. A brief review of known effects of noise on marine mammals. International Journal of Comparative Psychology 20:159-168.

Weilgart LS. 2018. The impact of ocean noise pollution on fish and invertebrates. Report for OceanCare, Switzerland.

Wilkens LA. 1986. The visual system of the giant clam Tridacna: behavioral adaptations. Biological Bulletin 170:393-408.

Wright AJ, Hatch LT, Aguilar de Soto N, Baldwin AL, Bateson M, Beale CM, Clark C, Deak T, Edwards EF, Fernandez A, Godinho A, Hatch LT, Kakuschke A, Lusseau D, Martineau D, Romero ML, Weilgart LS, Wintle BA, Notarbartolo-di-Sciara G, Cortes Martin V. 2007. Anthropogenic noise as a stressor in animals: A multidisciplinary perspective Journal of Comparative Psychology 20:250-273.

Ydenberg RC, Dill LM. 1986. The economics of fleeing from predators. Advances in the Study of Behavior 16:229-249.

Zhou Y, Radford AN, Magrath RD. 2019. Why does noise reduce response to alarm calls? Experimental assessment of masking, distraction and greater vigilance in wild birds. Functional Ecology 33:1280-1289. 


\section{Table $\mathbf{1}$ (on next page)}

Results from linear mixed effects model on variation in clam response

This model explains variation in giant clam responses (a-number of retractions in $60 \mathrm{~s}$, b-latency to close, c-latency to reemerge) following a multimodal stimulus experiment. The reference level was no stimulus. 
1 Table 1: Results from linear mixed effects model on variation in clam response

2 This model explains variation in giant clam responses ( $\mathrm{a}$ - number of retractions in $60 \mathrm{~s}, \mathrm{~b}-$

3 latency to close, c-latency to reemerge) following a multimodal stimulus experiment. The

4 reference level was no stimulus.

5

6 (a) Number of retractions in $60 \mathrm{~s}$

\begin{tabular}{lrr}
\hline Fixed Effects & Estimate \pm SE & P \\
\hline Intercept & $0.535 \pm 0.144$ & $<0.001$ \\
Trial Number & $0.0198 \pm 0.347$ & 0.569 \\
After Plume Presence & $-0.111 \pm 0.077$ & 0.150 \\
Size & $-0.323 \pm 1.18$ & 0.787 \\
Treatment & & \\
$\quad$ Flow & $0.280 \pm 0.05$ & $<0.001$ \\
$\quad$ Sound & $0.169 \pm 0.05$ & 0.001 \\
$\quad$ Flow + Sound & $0.277 \pm 0.05$ & $<0.001$ \\
\hline
\end{tabular}

Subject ID

0.010

0.101

7

8 (b) Latency to close

\begin{tabular}{lrr}
\hline Fixed Effects & Estimate \pm SE & P \\
\hline Intercept & $2.490 \pm 1.125$ & 0.032 \\
Trial Number & $-0.081 \pm 0.248$ & 0.743 \\
After Plume Presence & $0.188 \pm 0.550$ & 0.733 \\
Size & $19.685 \pm 9.437$ & 0.046 \\
Treatment & & \\
$\quad$ Flow & $0.177 \pm 0.348$ & 0.613 \\
$\quad$ Sound & $0.054 \pm 0.361$ & 0.882 \\
$\quad$ Flow + Sound & $0.749 \pm 0.353$ & 0.037 \\
\hline
\end{tabular}

Subiect ID

0.753

0.867

9

10 (c) Latency to reemerge

\begin{tabular}{lrr}
\hline Fixed Effects & Estimate \pm SE & P \\
\hline Intercept & $1.465 \pm 0.271$ & $<0.001$ \\
Trial Number & $0.012 \pm 0.051$ & 0.816 \\
After Plume Presence & $0.368 \pm 0.112$ & 0.002 \\
Size & $0.331 \pm 2.346$ & 0.889 \\
Treatment & & \\
$\quad$ Flow & $-0.114 \pm 0.074$ & 0.127 \\
$\quad$ Sound & $0.014 \pm 0.079$ & 0.859 \\
$\quad$ Flow + Sound & $0.024 \pm 0.074$ & 0.752 \\
\hline$\quad$ & 0.056 & 0.236 \\
\hline Subject ID & &
\end{tabular}

11 


\section{Figure 1}

Figure 1

A comparison of estimated marginal means of (a) $\log _{10}$ (number of partial retractions) (b) latency to close (c) $\log _{10}$ (Latency to reemerge) between all treatments. Bars indicate one standard error from the means. Letters above bars indicate treatments that are significantly different from each other. 


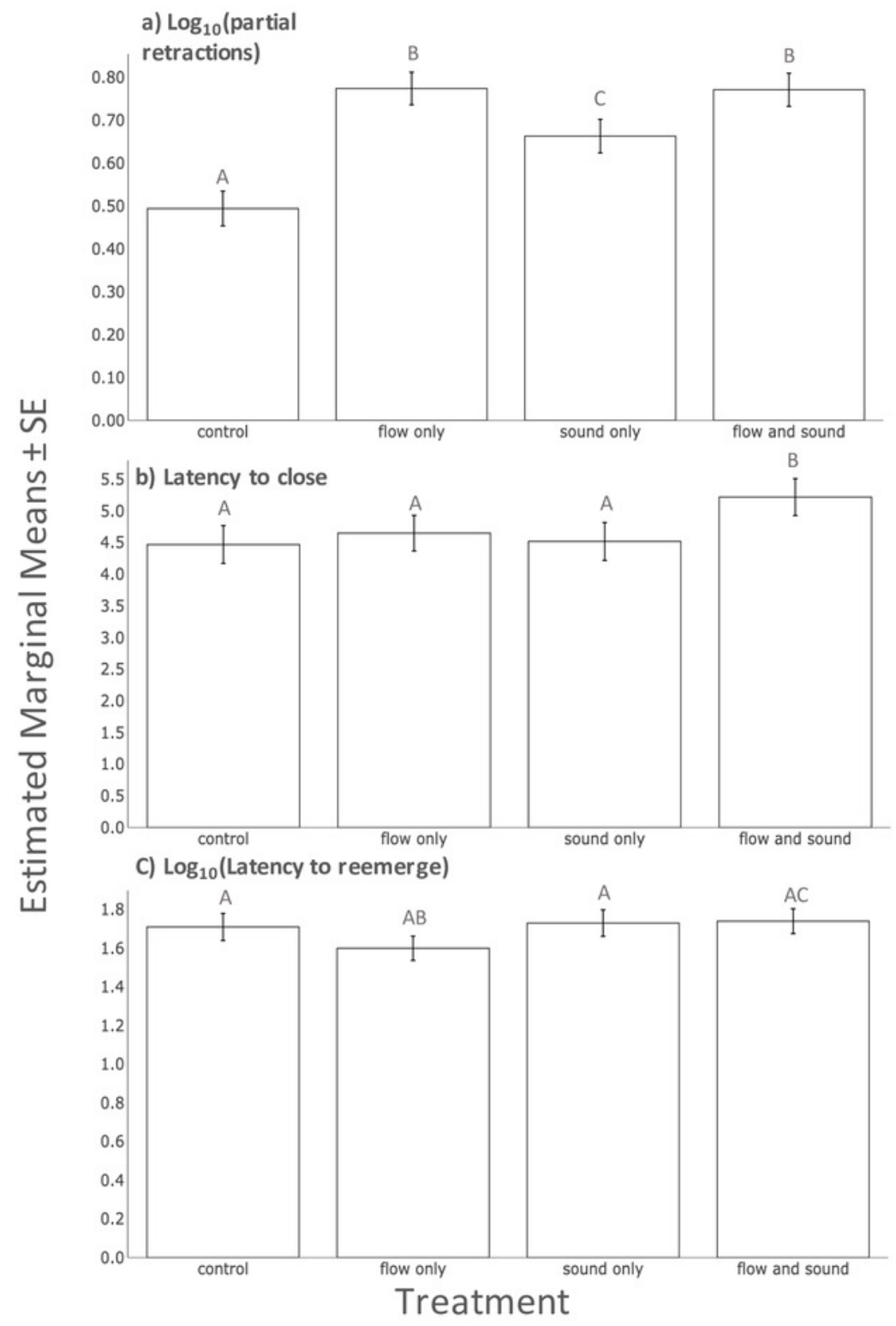

